\title{
CURATIVO À VÁCUO PARA COBERTURA TEMPORÁRIA DE PERITONEOSTOMIA
}

\author{
Vacuum dressing technique to temporary cover of laparostomy \\ Tiago Sarmento SIMÃO, Franklin Souza ROCHA, Felipe Barbosa MOSCON, \\ Rafael Ribeiro PINHEIRO, Fellipe Emanuel Amorim Santos BARBOSA, Leão FAIWICHOW
}

Trabalho realizado no Serviço de Cirurgia Plástica e Queimaduras do Hospital do Servidor Público Estadual de São Paulo HSPESP, São Paulo, SP, Brasil.

DESCRITORES - Peritoneostomia. Hérnia abdominal. Síndrome compartimental abdominal.
RESUMO - Introdução - O avanço nos cuidados com pacientes traumatizados ou com infecções intra-abdominais graves, trouxe importante ganho na sobrevida com o aumento de peritoneostomias. O manejo dos pacientes apresentou um problema de difícil solução: o fechamento primário sem tensão da cavidade abdominal. Objetivo - Apresentar proposta para cobertura temporária das peritoneostomias em pacientes submetidos à laparotomias de controle de danos ou laparotomias descompressivas por síndrome compartimental abdominal. Técnica - Realiza-se isolamento das alças intestinais das bordas da parede que são envolvidas por um filme de polietileno estéril multiperfurado com tesoura ou lâmina de bisturi, para impedir contato direto com a espuma. É colocado abaixo das bordas do defeito, entre o peritônio visceral e o parietal, e sobre ele uma espuma de poliuretano estéril fixada às bordas deixando o defeito livre de tensão quando o vácuo for aplicado. Ela é recoberta com um plástico adesivo de poliéster impregnado por iodo colado à pele e adicionada drenagem aspirativa contínua. O curativo é trocado entre três e cinco dias. Foi utilizado com sucesso em quatro pacientes onde foi possível o fechamento primário da cavidade abdominal após sete a 21dias. Destes, três tinham ficado com o abdome aberto após laparotomia por trauma (dois para controle de danos e um por impossibilidade de fechamento primário); o quarto tinha sido submetido à laparotomia descompressiva por síndrome compartimental abdominal. Conclusão - O curativo a vácuo mostrou ser boa opção para cobertura temporária de peritoneostomias permitindo fechamento mais rápido da ferida abdominal, reduzindo o número de reoperações e promovendo proteção das alças contra contaminação bacteriana.

\section{Correspondência: \\ Tiago Sarmento Simão \\ E-mail: tiagossimao@yahoo.com.br \\ Fonte de financiamento: não há \\ Conflito de interesses: não há}

Recebido para publicação: 21/01/2013

Aceito para publicação: 05/03/2013

HEADINGS - Laparostomy. Abdominal hérnia. Abdominal compartment syndrome.
ABSTRACT - Background - The advances in patient care with trauma or severe intra-abdominal infections, brought important gains in survival with the use of peritoneostomies. But the management of patients brought a difficult problem: the primary closure without tension of the abdominal cavity. Aim - To present a proposal for temporary coverage of peritoneostomies in patients undergoing damage control laparotomy or decompressive laparotomy for abdominal compartment syndrome. Technic - Isolation of the small intestine loops from abdominal internal; coverage of the intestinal surface with a polyethylene film multiperforated with sterile scissors or scalpel blade, to prevent direct contact with the foam. It is placed below the edges of the defect between the parietal and visceral peritoneum. Over it, a polyurethane sterile foam is fixed to the edges, leaving the defect tension free to the vacuum be applied. Another coverage with a plastic adhesive polyester impregnated with iodine stuck to skin is done, and, at the end, is added a drainage continuous aspiration system. The dressing is changed between three and five days. It was used successfully in four patients with primary closure of the abdominal cavity after seven to 21 days. Of these, three had open abdomen after laparotomy for trauma (two due to damage control and one for lack of primary closure); the fourth had been previously submitted to decompressive laparotomy for abdominal compartment syndrome. Conclusion - The vacuum dressing proved to be good choice for temporary coverage of peritoneostomies allowing faster closure of the abdominal wound, reducing the number of reoperations and providing protection against bacterial contamination of the intestinal loops. 


\section{INTRODUÇÃO}

A pós o desenvolvimento do conceito de laparotomias de controle de danos e do maior entendimento da síndrome compartimental abdominal nos últimos 20 anos $^{1-4}$, tornou-se cada vez mais frequente deixar o abdome aberto após laparotomias secundárias à traumas ou laparotomias descompressivas, quando o fechamento primário das paredes não é possível devido à tensão sobre os tecidos ou quando reexploração é programada. Laparotomias secundárias à traumas, quando prolongadas, resultam em agravamento da tríade acidose, coagulopatia e hipotermia, prejudicando o prognóstico dos pacientes. ${ }^{5} \mathrm{O}$ conceito de laparotomias de controle de danos implica em abreviação do tempo cirúrgico focando no controle do sangramento, prevenção da contaminação intraabdominal e proteção contra injúrias adicionais. Frequentemente são necessárias reoperações para restaurar a continuidade intestinal ou vascular, para inspeção da viabilidade visceral ou para controle de infecção. A utilização de fechamento temporário da parede abdominal sem tensão, facilita o acesso à cavidade peritoneal em futuras reoperações.

Ocurativo ideal para ser utilizado como fechamento temporário deve conter as vísceras intra-abdominais, protegê-las contra injúrias mecânicas, impedir o ressecamento das alças, impedir a contaminação da cavidade peritoneal e a perda de fluídos, causar mínima lesão nas paredes abdominais, possuir custo aceitável e, se possível, reduzir o edema visceral. ${ }^{6}$

O objetivo deste trabalho é apresentar proposta para cobertura temporária das peritoneostomias e foi desenvolvido no Hospital do Servidor Público Estadual de São Paulo, São Paulo, SP, Brasil. Serve como curativo temporário permitindo fechamento das paredes abdominais em função da constante tração medial exercida pelo vácuo sobre a fáscia abdominal.

\section{TÉCNICA}

Realiza-se isolamento das alças intestinais das bordas da parede (Figuras 1 A e B). A seguir, as alças são envolvidas por um filme de polietileno estéril multiperfurado com tesoura ou lâmina de bisturi, para impedir contato direto com a espuma. Ele é colocado abaixo das bordas do defeito, entre o peritônio visceral e o parietal (Figura 1C). Em seguida, uma espuma de poliuretano estéril (V.A.C.; KCI International, San Antonio, TX, USA) é colocada sobre o filme plástico, preenchendo o defeito abdominal e fixado às bordas com pontos de náilon para segurar a espuma, porém deixando as bordas do defeito livres de tensão quando o vácuo for aplicado (Figura 1D).

Um dreno de sucção do tipo Portovac ${ }^{\circledR}$ de

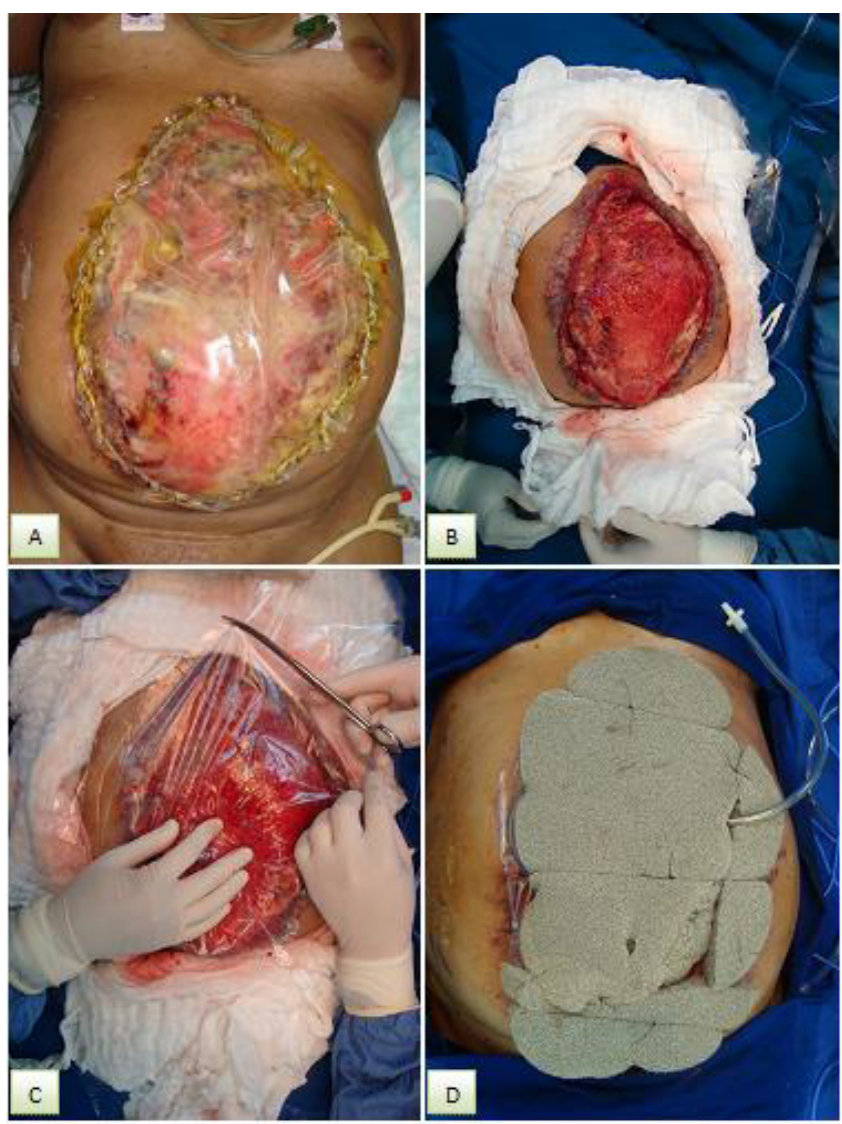

FIGURA 1 - A - Paciente com peritoneostomia descompressiva por síndrome compartimental abdominal; B - isolamento das alças intestinais das bordas da parede; C colocação de filme plástico protegendo as alças; D - espuma estéril colocada sobre o defeito, fixada por pontos, juntamente com dreno de sucção.

calibre 3/16 $(4,8 \mathrm{~mm})$ é transfixado na espuma, saindo superolateralmente à ferida (Figura 1D). A pele adjacente é secada e pintada com tintura de benjoim. A espuma é então coberta com um plástico adesivo de poliéster impregnado por iodo ( $3 \mathrm{M}$ Ioban $^{\mathrm{TM}} 2$ ) que é colado à pele (Figura 2A).

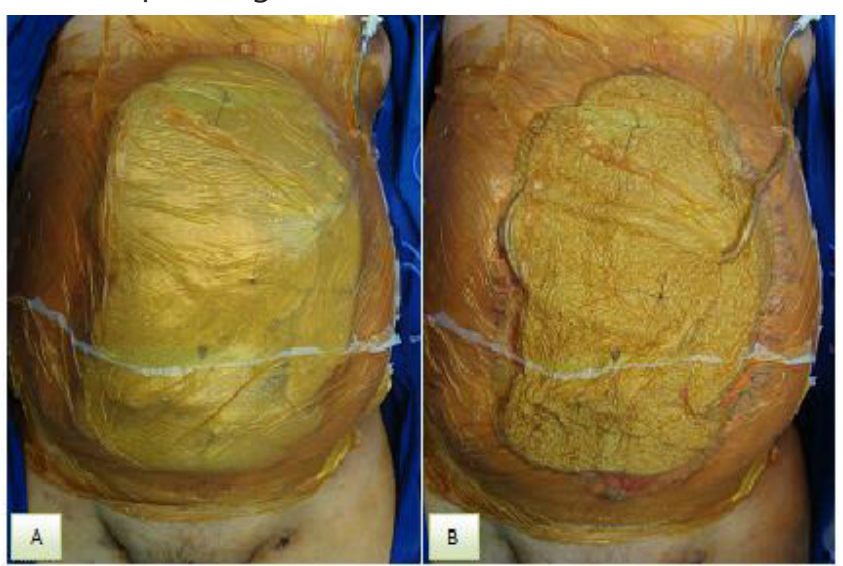

FIGURA 2 - A - Curativo ocluído com plástico adesivo antes da aplicação do vácuo; B - após aplicação do vácuo, resultando em contração da ferida e tração medial das bordas 
O dreno é conectado a um frasco coletor de secreções e a um aspirador portátil, sendo mantido em aspiração contínua de $125 \mathrm{mmHg}$ em 24 horas por dia. O curativo é trocado a cada três a cinco dias, até que se consiga fechamento definitivo da parede ou até que se tenha leito adequado para enxertia cutânea. As trocas devem ser realizadas preferencialmente no centro cirúrgico em ambiente estéril, porém pode também ser realizada na unidade de terapia intensiva se necessário.

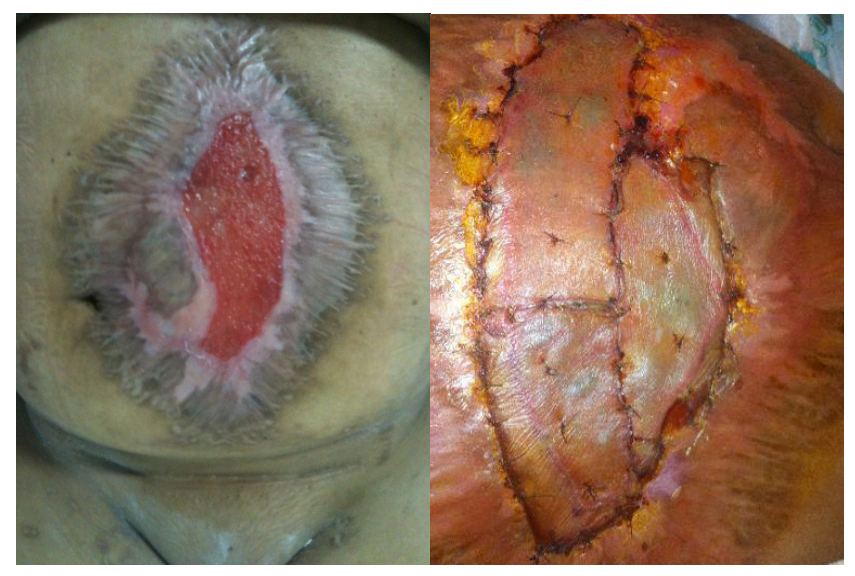

FIGURA 3 - Aspecto da ferida após 19 dias de curativo à vácuo, mostrando retração cicatricial, bom tecido de granulação e enxertia de pele parcial

Seis pacientes foram submetidos à tentativa de fechamento da parede abdominal utilizando com a técnica descrita. Todos foram operados inicialmente pela equipe de cirurgia geral, que realizou laparotomia em consequência a traumas abdominais ou síndrome compartimental abdominal, e deixados em peritoneostomia. Em quatro foi possível o fechamento primário da cavidade abdominal após sete a 21dias. Destes, três tinham ficado com o abdome aberto após laparotomia por trauma (dois para controle de danos e um por impossibilidade de fechamento primário); o quarto paciente foi submetido à laparotomia descompressiva por síndrome compartimental abdominal.

Em dois casos não foi possível fechamento primário, pois já se apresentavam com uma a duas semanas após a laparotomia descompressiva com bolsa de Bogotá; possuíam aderências fibrosas das alças com a parede impedindo descolamento seguro e aproximação das bordas. Neles optou-se por trocas seriadas do curativo até ser identificado tecido de granulação recobrindo as alças e enxertia de pele parcial, resultando em hérnia ventral intencional. Não foram observadas formação de fístulas, nem infecção de ferida operatória.

\section{DISCUSSÃO}

A técnica tem como objetivo a cobertura temporária da peritoneostomia, protegendo as alças intestinais de traumas e ressecamento. Oportuniza reduzir o edema e possibilita o fechamento mais precoce da parede abdominal pela tração exercida sobre as bordas da ferida. Para os casos tardios, quando as alças já estão cobertas por intensa fibrose cicatricial impedindo descolamento seguro, o curativo à vácuo estimula a formação de tecido de granulação sobre as alças, possibilitando enxertia cutânea.

Com o aumento da frequência das peritoneostomias, várias técnicas para fechamento temporário da ferida abdominal foram propostas, incluindo desde fechamento apenas da pele deixando um largo defeito da parede para ser fechado posteriormente ${ }^{7}$, até uso de diversos materiais sintéticos suturados à pele ou às estruturas fibromusculares da parede abdominal. ${ }^{8}$ O grande inconveniente do uso destes materiais é o risco de aderência das alças à tela, que podem ser lesadas durante reoperações. As telas em contato direto com as alças intestinais podem erodi-las, variando a intensidade na dependência do material utilizado.

O uso do curativo sob pressão negativa estimula aumento da perfusão tecidual, além de reduzir a tensão sobre as bordas da ferida. Minimiza o risco de necrose, ao mesmo tempo que promove contração da ferida aproximando as bordas. Permite assim fechamento mais rápido da ferida, menor tempo de internação e menor número de reoperações. Este curativo permite controle das perdas de fluidos peritoneais, debridamento da ferida, diminuição da contaminação bacteriana, remoção de fluido intersticial e redução do edema visceral. Por não exigir suturas, o curativo à vácuo evita trauma aos tecidos da parede abdominal e diminui a dificuldade técnica de fechamento temporário do defeito durante reintervenções cirúrgicas. A utilização de um filme plástico estéril como interface entre a espuma e as alças é importante pois, além de proteger e conter as vísceras, impede a aderência delas ao peritônio da parede abdominal, dificultando o posterior fechamento. ${ }^{9}$

Barker et al, foram os primeiros a descrever o uso de curativo à vácuo para fechamento temporário abdominal, utilizando técnica um pouco diferente. Em publicação recente revisaram 112 casos operados ao longo de sete anos alcançando fechamento parietal em $55,4 \%$ dos casos e com poucas complicações. ${ }^{6}$

As complicações mais comuns deste tipo de técnica incluem infecção, sangramento e fístulas enterocutâneas. Na maioria dos casos a infecção se limita à ferida operatória, porém são relatados casos de infecções intra-cavitárias. As fístulas encontradas na maioria dos relatos na literatura não estão relacionadas diretamente à colocação do curativo à vácuo, mais sim à presença de traumatismo pancreático e à presença de deiscência nas anastomoses intestinais. A ocorrência de fístulas, porém, é mais comum quando alguma alça encontra-se exposta à espuma, sendo minimizada com a proteção do conteúdo intestinal pelo filme plástico. 
Suliburk et $\mathrm{al}^{10}$, fizeram revisão retrospectiva de 36 pacientes submetidos a curativo à vácuo em peritoneostomias após traumas severos, realizando fechamento com sucesso em $86 \%$ dos casos no período de três a 18 dias. Não foram identificadas eviscerações, abscessos ou infecções de ferida. Nos pacientes em que não foi conseguido fechamento, dois desenvolveram fístulas pancreática e colônica, secundária a perfuração destes órgãos durante o trauma.

\section{CONCLUSÃO}

O curativo à vácuo mostrou-se boa opção para cobertura temporária de peritoneostomias por permitir fechamento mais rápido da ferida abdominal, redução do número de reoperações e proteção adequada das alças contra contaminação bacteriana.

\section{REFERÊNCIAS}

1. Rotondo MF, Schwab CW, McGonigal MD et al. "Damage Control": an approach for improved survival in exsanguinating penetrating abdominal injury. J Trauma 1993; 35:375-382.
2. Burch JM, Ortiz VB, Richardson RJ. Abbreviated laparotomy and planned reoperation for critically injured patients. Ann Surg. 1992; 215:476-484.

3. Chang MC, Miller PR, D'Agostino R Jr, Meredith JW: Effects of abdominal decompression on cardiopulmonary function and visceral perfusion in patients with intra-abdominal hypertension. J Trauma 1998; 44:440-445.

4. Moore $A F$, Hargest $R$, Martin $M$, Delicata RJ: Intra-abdominal hypertension and the abdominal compartment syndrome. $\mathrm{Br} J$ Surg 2004; 91:1102-1110.

5. Moore EE. Staged laparotomy for the hypothermia, acidosis and coagulopathy syndrome. Am J Surg 1996; 172:405-410.

6. Barker DE, Kaufman HJ, Smith LA, et al. Vacuum pack technique of temporary abdominal closure: a 7-year experience with 112 patients. J Trauma 2000; 48:201-207.

7. Fabian TC, Croce MA, Pritchard FE, et al. Planned ventral hernia: staged management for acute abdominal wall defects. Ann Surg. 1994; 219:643-653.

8. Porter JM. A combination of Vicryl and Marlex mesh: a technique for abdominal wall closure in difficult cases. J Trauma. 1995; 39:1178-1180.

9. Miller PR, Meredith JW, Johnson JC, Chang MC. Prospective evaluation of vacuum-assisted fascial closure after open abdomen. Planned ventral hernia rate is substantially reduced. Ann Surg 2004;239:608-616.

10.Suliburk JW, Ware DN, Balogh Z, et al. Vacuum-assisted wound closure achieves early fascial closure of open abdomens after severe trauma. J Trauma 2003; 55:1155-1160. 